\title{
Editorial
}

\section{What's in a name?}

It is just over a decade since the term "behavioural psychotherapy" was first introduced to the unsuspecting British public, or, more acurately to the small group of psychologists, psychiatrists and nurses who managed to squeeze their way past the twin bouncers of Bob Sharpe and Francis Lillie to attend the inaugural meeting of what came to be known as the British Association for Behavioural Psychotherapy. There had been a heated debate, I gather, beforehand about the choice of name, with a strong contingent favouring "behaviour therapy", but in the end the Marksists won the day (Isaac, not Karl) and "behavioural psychotherapy", it became. Since then the organization has flourished, its membership steadily increased and its parochial newsletter transformed into the erudite journal you now have in your hands.

But was the debate misguidedly concentrated on the noun rather than the adjective? Should we have been concerned more with the epithet "behavioural"? After all, the distinction between "therapy" and "psychotherapy" is a fine one, whereas "behavioural" has quite definite connotations. But in 1972 there was little room for doubt about the importance of the adjective: it was after all what brought us together. There was more concern to avoid the possible taint of being known as a form of psychotherapy!

It all seems rather a long time ago. What of the way behavioural psychotherapists describe themselves today? A random survey of practising psychotherapists in the United Kingdom (or, to be honest, a straw poll of my immediate colleagues in the Warneford Hospital) revealed considerable ambivalence about the use of any label and a preference for less definite descriptions such as "taking a behavioural or cognitive-behavioural approach". When pressed, however, two plumped for "behavioural therapist" (not "behaviour therapist" since this might be construed as too narrow), one for "cognitive-behaviour therapist" and another preferred the neutral term "psychotherapist". (However, he admitted to having been Tavistock trained and had never been part of the behavioural movement.) So the epithet "behavioural" survives (at least in Oxford) in one form or another. But what does it actually mean to call oneself a behavioural psychotherapist?

In the heady days of the behaviour therapy revolution, writers (or, at least one well-known writer) knew precisely what it meant to be a behaviour therapist: 
Behaviour therapy can be defined as the attempt to alter human behaviour and emorion in a beneficial manner according to the laws of modern learning theory (Eysenck, 1964, p. 1).

But most of us proved to be far less confident than Hans Eysenck. It was unclear to many what "the laws of modern learning theory" consisted of, and, if one were able to enunciate key psychological principles (e.g. reinforcement, extinction), whether they were in any real sense scientific laws. More importantly, the practising behaviour therapists knew that a large part of their behaviour as therapists was not in fact governed by any laws or principles of modern learning theory at all. Indeed, as we all know, learning theory ceased to play a significant part in later definitions of behaviour therapy and few practitioners have had the temerity to justify their pactice with reference to scientifically-established laws. It is doubtful that many modern behavioural psychotherapists would claim a strong allegiance to learning theory. The widely cited A.A.B.T. definition of behaviour makes no mention of it:

Behaviour therapy involves primarily the application of principles derived from research in experimental and social psychology for the alleviation of human suffering and the enhancement of human functioning (Franks and Wilson, 1975, p. 2).

Kazdin (1978) in his comprehensive account of the history of behaviour therapy describes contemporary behaviour modification as "more an advocation of scientific approach toward treatment and clinical practice rather than a particular conceptual stance" (p.375). But if behavioural psychotherapy is not defined in terms of its behavioural or learning theory origins, but is seen rather as a methodological approach, then is not the term "behavioural" misleading? After all, there are non-behavioural psychotherapies which are derived from experimental and social pscyhology, for example, those based on attribution theory, or the cognitive therapies. And behaviourism has never had a premium upon scientific methodology or therapy evaluation, even if behaviour therapists have been amongst the leading advocates of outcome research in psychotherapy. Moreover, the striking result of the "cognitive revolution" has been to take behavioral psychotherapists well beyond their previous adherence to objective behaviour (always tenuous at best) and into the murky realm of thought, beliefs, fantasies and other spectral cognitions. Are we not all cognitive-behaviourists now?

Despite these changes, we cling steadfastly to the old terms. Why? Perhaps it is because it is simply a matter of tradition and established practice. Perhaps we need a peg on which to hang our therapeutic practices, regardless of the accuracy of its true meaning. Terry Wilson, in a light-hearted defence of the term "behavioural therapy", got nearest to its importance: 
At the risk of being sentimental, as far as brand names go, behavior therapy has much to recommend it. It was useful in providing the flag around which a variety of intellectual forces rallied in changing the face of much of clinical practice . . . Moreover, as a label it does not seem to have exercised an unduly restrictive effect on scientific development. If a thousand flowers did not bloom, several distinctive emphases or divisions did develop, undoubtedly nurtured by the overall spirit of critical, including self-critical enquiry of most of those who aligned themselves with behavior therapy (Wilson, 1978, p. 95).

If behaviour therapy is associated with the spirit of critical enquiry, we can expect the allegiance to the name to continue. There is, after all, nothing stronger or more steadfast than a spiritual movement.

\section{References}

EysenCK, J. J. (Ed) (1964). Experiments in Behavtour Therapy. Readings in Modern Methods of Treatment of Mental Disorders Derived from Learning Theory. Oxford: Pergamon Press.

Franks, C. M. and WiLson, G. T. (1975). Annual Revieu' of Behatior Therapy. Theory and Practice. New York: Brunner/Mazel.

KazDIN, A. E. (1978). History of Bebavior Modification. Experimental Foundations of Contemporary Research. Baltimore: University of Park Press.

WILSON, G. T. (1978). On the much discussed nature of the term "behavior therapy". Behavior Therapy 9, 89-98. 